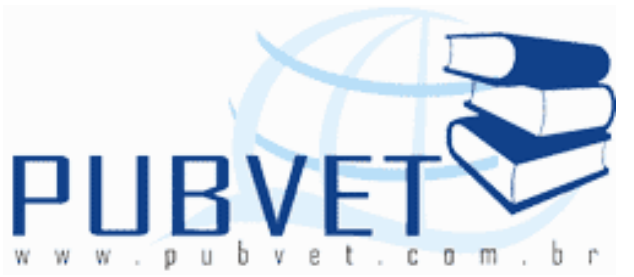

PUBVET, Publicações em Medicina Veterinária e Zootecnia.

\title{
Monitoramento sanitário de colônia de camundongos BALB/c mantidos em biotério convencional
}

\author{
Tânia Cristina Pereira ${ }^{1}$, Sílvia Cristina Barboza Pedrini ${ }^{2}$, Heloísa Helena \\ Escudero $^{3}$, Reinaldo Valério Germino ${ }^{3}$, Patrícia Sammarco Rosa
}

${ }^{1}$ Bióloga

${ }^{2}$ Médica Veterinária

${ }^{3}$ Biologista

Instituto Lauro de Souza Lima

Rod. Cmte. João Ribeiro de Barros, km 225/226 - Bauru, SP - Cx postal 3021 CEP 17034-971 - F.: (14) 3103-5886 - endereço eletrônico:

silviapedrini@yahoo.com.br

\section{Resumo}

O objetivo deste estudo foi avaliar o estado sanitário da colônia de camundongos BALB/c e as condições ambientais do Biotério do Instituto Lauro de Souza Lima, através de exames parasitológicos e microbiológicos. Utilizando-se meios de cultura enriquecidos e seletivos, procurou-se identificar agentes potencialmente patogênicos para os animais e zoonóticos, a partir de pele, pelos, trato respiratório e entérico dos animais, além da microbiota fúngica ambiental. Pesquisou-se a presença de Mycoplasma sp. e Bordetella sp. em traqueia e fungos em pele e pelos, além de exames parasitológicos e pesquisa de Salmonella spp. e enterobactérias em amostras de conteúdo do 
ceco dos animais. Para monitoramento do ambiente, coletaram-se amostras de diferentes locais do interior do biotério. Após macro e microcultivo fúngicos, foram identificados Cladosporium sp., Acremonium sp., Aspergillus sp., Curvularia sp. e Trichophyton mentagrophytes. O exame micológico de pele e pelos resultou negativo para $100 \%$ das amostras. Não foi observado crescimento de patógenos respiratórios, nem de Salmonella spp. As bactérias isoladas são constituintes da microbiota entérica normal de animais em condições convencionais: Escherichia coli, Enterobacter aerogenes, Enterobacter cloacae, Proteus mirabilis, Klebsiella spp., Providencia stuart, Pseudomonas putida. O exame parasitológico demonstrou a presença de Strongyloides stercoralis, Syphacia obvelata, Aspiculuris tetraptera e Ancylostoma sp.. O trabalho realizado demonstrou grande valor diagnóstico, tanto para avaliação da saúde dos animais de laboratório, como para uma análise qualitativa da microbiota fúngica ambiental, devendo ser implantado como rotina no biotério.

Palavras-chave: camundongo, monitoramento sanitário, animais de laboratório.

\title{
Health monitoring of the of BALB/c mice colony kept in a conventional animal facility
}

\begin{abstract}
The aim of this work was to evaluate the health status and environmental conditions of the colony of BALB/C mice maintained in an Animal Facility of the Lauro de Souza Lima Institute. Parasitological and microbiological tests with enriched and selective culture media were used to identify zoonotic and potentially pathogenic agents from skin, hair, respiratory and enteric tracts of the animals and fungal flora of the environment. This study proposed to verify colonization of Mycoplasma sp. and Bordetella sp. in trachea, fungi in skin and hair, as well as perform parasitological examination, Salmonella spp. and enterobacteria isolation from cecum of sampled animals. In addition serum of
\end{abstract}


animals were tested against different viral and bacterial antigens and against Toxoplasma gondii antigen.For environmental monitoring samples were collected from different locations. After macro and microculture, the fungi identified were Cladosporium sp. Acremonium sp., Aspergillus sp., Curvularia sp. and Trichophyton mentagrophytes. Mycological examination of the skin was negative for $100 \%$ of the samples. There was no growth of respiratory pathogens or Salmonella spp. The bacteria isolated in the present study consist of the normal enteric microbiota of animals in conventional conditions: Escherichia coli, Enterobacter aerogenes, Enterobacter cloacae, Proteus mirabilis, Klebsiella spp. Providencia stuart and Pseudomonas putida. The parasitological examination showed the presence of Strongyloides stercoralis, Syphacia obvelata, Aspiculuris tetraptera and Ancylostoma sp. Serology resulted negative for all tested antigens. The techniques used in this work showed to be valuable for diagnostic purpose, to assess the health of laboratory animals, as well as for qualitative analysis of environmental fungal microbiota, thus it should be implemented as a routine in the animal house.

Keywords: mouse, healthy monitoring, laboratory animals.

\section{Introdução}

Grande parte dos avanços no conhecimento sobre enfermidades infecciosas, microbiologia, imunologia, farmacologia e patologia tem sido possível graças à existência de modelos experimentais (Molinaro, 2009).

As instalações onde são produzidos e mantidos estes animais de experimentação são denominadas biotérios. Neles devem ser produzidas e alojadas espécies animais destinados a atender às atividades de ensino e pesquisa, conforme a missão da instituição. Os biotérios podem se distinguir quanto às atividades neles realizadas. Nos biotérios de produção são criados animais a partir de matrizes selecionadas para linhagens específicas. Sua edificação deve ocorrer preferencialmente em áreas isoladas distantes dos centros urbanos. Nos biotérios de experimentação são alojados os animais que 
serão utilizados para ensino e pesquisa. Nesse caso os animais permanecem no biotério por um determinado período experimental, durante o qual devem ser observados rigorosamente o início, duração e término, bem como a quantidade e espécie animal a ser utilizada no experimento. A prática aconselha que esse tipo de construção deva ser próximo ao laboratório de pesquisa (Cardoso, 2001).

Para manutenção do padrão sanitário num biotério é necessária a implantação de barreiras sanitárias para proteção da população humana e animal, envolvidas nos processos de produção e experimentação (Cardoso, 2001). Barreira sanitária é, portanto, um sistema que combina aspectos construtivos, equipamentos e métodos operacionais que buscam estabilizar as condições ambientais das áreas restritas, minimizando a probabilidade de patógenos ou outros organismos indesejáveis contactarem a população animal de áreas limpas.

As barreiras sanitárias adotadas dependem do padrão sanitário que se pretende obter. Todas as barreiras devem ser implantadas para proporcionar bem estar ao animal garantindo que nada influencie no resultado do experimento. São fatores importantes o controle do macroambiente (temperatura, umidade relativa do ar, luminosidade e ruídos), controle do microambiente (qualidade da cama, dieta e hidratação), instalações adequadas com portas e janelas vedadas, filtros de ar, sistema de exaustão, higienização do ambiente e esterilização de materiais, observação de boas práticas de laboratório para manejo dos animais, quarentena para animais recémadquiridos, higiene pessoal dos bioteristas, utilização de equipamentos de segurança individual (máscaras, gorros, uniformes, propés e luvas), avaliação laboratorial periódica, treinamento e qualificação dos recursos humanos (Raimundo e Goldim, 2002).

As barreiras sanitárias devem ser validadas de forma a assegurar a qualidade dos animais produzidos e/ou utilizados na pesquisa. As infecções subclínicas são muito mais comuns do que as doenças em animais de experimentação, ainda assim podem causar alterações nos resultados de 
experimentos, acarretando perdas econômicas e diminuição da produtividade científica (Molinaro, 2009). Portanto, um fator essencial para reprodutibilidade e confiabilidade dos protocolos experimentais só é possível através de um monitoramento rigoroso da qualidade sanitária dos animais utilizados na pesquisa biomédica.

O monitoramento sanitário é um conjunto de metodologias e procedimentos estabelecidos realizados em colônias de animais em intervalos regulares, que variam de acordo com o padrão sanitário da colônia, e visam detectar a presença ou não de agentes infecciosos (Luca et al., 1996).

\section{Material e Métodos}

\section{Animais}

Trinta e um camundongos BALB/c de ambos os sexos, com idade variando de 4 semanas ( $30 \%$ dos animais) a 12 meses de idade (70\% dos animais) foram divididos em três grupos ( $G_{1}$ e $G_{2}$ e $\left.G_{3}\right)$, onde $G 1(n=10) ; G 2$ $(n=11) ; G 3(n=10)$, mantendo a proporção da idade.

\section{Sorologia}

Os animais do grupo G1 foram anestesiados, via intraperitoneal, com $100 \mathrm{mg}$ de quetamina e $10 \mathrm{mg}$ de xilazina e submetidos à punção cardíaca para retirada de sangue total, que foi colocado em tubos cônicos estéreis de $1,5 \mathrm{ml}$ para obtenção dos soros, devidamente identificados e armazenados a $-20^{\circ} \mathrm{C}$ para envio ao Laboratório de Controle de Qualidade Animal, Centro Multidiciplinar para Investigação Biológica, CEMIB, Unicamp.

Os antígenos testados foram: vírus da hepatite murina (MHV), vírus da encefalomielite de Theiler (TMEV-GD), vírus Sendai, vírus diminuto do camundongo (MVM), vírus da ectromelia, vírus da coriomeningite linfocitária ( $L C M)$, adenovírus tipo 1 (MAD), rotavírus do grupo A, reovírus tipo 3, além dos antígenos para Bordetella bronchiseptica, Corynebacterium kutscheri, Mycoplasma pulmonis, Clostridium piliforme e Toxoplasma gondii. 


\section{Coleta de amostras}

Os camundongos do grupo G1 foram eutanasiados por sangria branca, após retirada total do sangue. Já os animais dos grupos $G_{2}$ e $G_{3}$ foram eutanasiados em câmara de $\mathrm{CO}_{2}$. . Posteriormente foram colocados no interior de uma câmara asséptica e fixados em decúbito dorsal em um suporte para dissecção. A face ventral do animal foi submetida a antissepsia com álcool $70 \%$. A pele foi então rebatida com ajuda de pinça e tesoura estéreis. Foi feita coleta de material com fita anal para pesquisa direta de parasitas.

\section{Avaliação micológica}

\section{- Animais}

Foram coletados pelos para exame micológico com pinça estéril. 0 material foi semeado nos meios Agar Saboraud e Mycosel, os quais foram incubados a $25^{\circ} \mathrm{C}$ durante 30 dias, para verificar a ocorrência de fungos dermatófitos e leveduras na pele dos animais.

\section{- Ambiente}

Foram utilizados swabs em solução salina estéril, em diferentes regiões das instalações, equipamentos e fômites das salas de camundongos. O material foi semeado em tubos contendo Ágar Mycosel e Ágar Sabouraud acrescido de $30 \mathrm{mg}$ de cloranfenicol. Os tubos foram incubados a $25^{\circ} \mathrm{C}$ durante 30 dias. Em seguida foi realizado o microcultivo para a identificação das colônias. Foram avaliadas paredes da frente, laterais e fundo antes e após limpeza e desinfecção com hipoclorito de sódio a $0,5 \%$; janela e portas internas e externas sem limpeza e desinfecção; maravalha imediatamente após autoclavagem, estocada há uma semana, com 24 e 72 horas de uso; gaiolas imediatamente após a lavagem, estocadas há uma semana, com 24 e 72 horas de uso; grades imediatamente após a lavagem e em uso há uma semana; bebedouros lavados e secos; tambor de ração, uniformes, botas e luvas dos funcionários. 


\section{- Swab de traqueia}

As traqueias dos animais foram dissecadas e abertas longitudinalmente com uma lâmina de bisturi. Seus conteúdos foram coletados com um swabs estéreis umedecidos com água destilada estéril e imediatamente semeados nos meios: Ágar Sangue (para mesófilos), Bordet-Gengou (para Bordetella bronchiseptica), Loffler (para Corynebacterium sp.), Caldo PPLO "Pleuropneumonia-like organisms" (para Mycoplasma spp.)

As amostras foram incubadas a $37^{\circ} \mathrm{C}$ por 24 horas. Após esse período foi feita a primeira leitura e verificado o crescimento positivo ou negativo. Os tubos contendo o caldo PPLO foram incubados a $37^{\circ} \mathrm{C}$ por 72 horas. Após esse período foi realizada uma leitura. As colônias foram isoladas e coradas pelo método de Gram e em seguida foram realizadas provas bioquímicas catalase, coagulase, manitol, Dnase, EPM-Mili, citrato e uréia para identificação de espécies.

\section{- Conteúdo do ceco}

Os cecos dos animais foram abertos com auxílio de tesoura estéril e seu conteúdo foi coletado com uma alça descartável estéril e semeado em meios de cultura MacConkey (para Gram negativos), Salmonella-Shigella (SS), Cetrimide (Pseudomonas sp.), Manitol Salt Agar ( Staphylococcus), Ágar Sangue (Enterococos sp., Micrococus sp., Streptococus sp.). Os meios foram incubados por 48 horas a $37^{\circ} \mathrm{C}$. Após este período, quando houve crescimento de colônias, estas foram isoladas e identificadas bioquimicamente juntamente com as amostras isoladas de traqueia.

O ceco foi retirado e colocado em um tubo plástico estéril para exame parasitológico, pesquisa de protozoários, ovos, cistos, larvas e helmintos adultos. Foi utilizado o método de Hoffman. 


\section{Resultados}

Os resultados de exame micológico foram negativos para todas as amostras de pelo dos grupos G1, G2 e G3. Quanto ao ambiente, em uma das amostras (grade com uma semana de uso) foi isolado um patógeno importante, o Trichophyton mentagrophytes; os demais fungos isolados são considerados ambientais e oportunistas (tabela 1 ).

Tabela 1. Culturas de fungos positivas de amostras coletadas em diferentes regiões das instalações, equipamentos e fômites das salas de camundongos do biotério do ILSL.

\begin{tabular}{|l|l|}
\hline Fungo isolado & Local isolado \\
\hline Cladosporium sp. & $\begin{array}{l}\text { Maravalha/ Uniformes dos funcionários/ Janela/ } \\
\text { Parede }\end{array}$ \\
\hline Aspergillus sp. & Grades/ Tambor de ração \\
\hline Acremonium sp. & Parede do fundo \\
\hline $\begin{array}{l}\text { Trichophyton } \\
\text { mentagrophytes }\end{array}$ & Grades com uma semana de uso \\
\hline
\end{tabular}

Não foram observados ectoparasitas na pele dos animais. No exame parasitológico direto, todas as amostras resultaram negativas. Pelo método de sedimentação foram observados alguns animais parasitados por oxiurídeos. No G1 4/10 (40\%) animais estavam infectados pelos organismos Syphacia obvelata e Aspiculuris tetraptera. No G2 4/11 (36\%) estavam animais infectados pelos mesmos organismos. No grupo G3 encontramos animais infectados com Strongyloides sp. 5/10 (50\%) e animais infectados com Ancystoloma sp. 2/10 (20\%).

Quanto ao exame microbiológico, nos grupos G1, G2 e G3 foi verificada somente a presença de bactérias pertencentes à microbiota normal de traquéia 
e ceco de roedores, (tabelas 2 e 3), com exceção do Staphylococcus aureus, que pode colonizar a pele dos animais.

Tabela 2. Porcentagem de animais com culturas positivas de amostras coletadas da traquéia de camundongos BALB/C mantidos em biotério convencional no ILSL. Resultados obtidos nos grupos G1 $(n=10)$ G2 $(n=11)$; $\mathrm{G} 3(\mathrm{n}=10)$.

\begin{tabular}{|l|l|l|l|}
\hline Organismo pesquisado & G1 (\%) & G2 (\%) & G3(\%) \\
\hline Bordetella bronchiseptica & 0 & 0 & 0 \\
\hline Corynebacterium sp. & 0 & 0 & 0 \\
\hline Staphylococcus aureus & 30 & 27 & 27 \\
\hline
\end{tabular}

Tabela 3. Porcentagem de animais com culturas positivas de amostras coletadas do ceco de camundongos BALB/c mantidos em biotério convencional no ILSL. Resultados obtidos nos grupos G1 $(n=10) ; G 2(n=11) ; G 3(n=10)$

\begin{tabular}{|l|l|l|l|}
\hline Organismo isolado & G1 (\%) & G2 (\%) & G3(\%) \\
\hline $\begin{array}{l}\text { Escherichia coli } \\
\text { aerogenes }\end{array}$ & 70 & 91 & 100 \\
\hline $\begin{array}{l}\text { Enterobacter } \\
\text { cloacae }\end{array}$ & 10 & 0 & 0 \\
\hline Klebsiella spp. & 0 & 0 & 0 \\
\hline Proteus mirabilis & 30 & 9 & 0 \\
\hline $\begin{array}{l}\text { Providencia } \\
\text { stuartii }\end{array}$ & 0 & 0 & 0 \\
\hline $\begin{array}{l}\text { Pseudomonas } \\
\text { putida }\end{array}$ & 0 & 0 & 10 \\
\hline Salmonella spp. & 0 & 0 & 20 \\
\hline
\end{tabular}


A negatividade dos soros testados (tabela 4) contra os diferentes antígenos indica ausência de infecção subclínica na colônia.

Tabela 4. Resultado das provas sorológicas dos camundongos BALB/C mantidos em biotério convencional no ILSL.

\begin{tabular}{|c|c|c|c|c|c|c|c|c|c|c|}
\hline Antígeno / método & C5 & C6 & C7 & C9 & 10 & 11 & 12 & 13 & 14 & $\begin{array}{c}\text { \% de } \\
\text { infecção }\end{array}$ \\
\hline MHV- IFI & - & - & - & - & - & - & - & - & - & 0,0 \\
\hline TMEV-GD VII - IFI & - & - & - & - & - & - & - & - & - & 0,0 \\
\hline Sendai - IFI & - & - & - & - & - & - & - & - & - & 0,0 \\
\hline MVM - IFI / IHA & - & - & - & - & - & - & - & - & - & 0,0 \\
\hline Ectromélia - IFI & - & - & - & - & - & - & - & - & - & 0,0 \\
\hline LCM - IFI & - & - & - & - & - & - & - & - & - & 0,0 \\
\hline MAD tipo 1 (FL) - IFI & - & - & - & - & - & - & - & - & - & 0,0 \\
\hline Rota grupo A ( EDIM ) - IFI & - & - & - & - & - & - & - & - & - & 0,0 \\
\hline REO-3 - IFI & - & - & - & - & - & - & - & - & - & 0,0 \\
\hline $\begin{array}{l}\text { Bordetella bronchiseptica - } \\
\text { MA }\end{array}$ & - & - & - & - & - & - & - & - & - & 0,0 \\
\hline $\begin{array}{l}\text { Corynebacterium kutscheri - } \\
\text { MA }\end{array}$ & - & - & - & - & - & - & - & - & - & 0,0 \\
\hline $\begin{array}{l}\text { Mycoplasma pulmonis-IFI } \\
\text { /Elisa }\end{array}$ & - & - & - & - & - & - & - & - & - & 0,0 \\
\hline Clostridium piliforme - IFI & - & - & - & - & - & - & - & - & - & 0,0 \\
\hline Toxoplasma gondii - IFI & - & - & - & - & - & - & - & - & - & 0,0 \\
\hline
\end{tabular}

$\mathrm{C}=$ camundongo (soros obtidos de cada animal do grupo G1); - = negativo

IHA = Reação de Inibição da Hemaglutinação; Soros testados nas diluições $1 / 10$ até $1 / 320$

IFI = Reação de Imunofluorescência Indireta; Soros testados na diluição 1/20 :

$+=$ imunofluorescência fraca ( título $1 / 20$ a $1 / 40$ )

$++=$ imunofluorescência média ( título $1 / 40$ a 1/80 )

$+++\quad$ imunofluorescência forte (título $>1 / 80$ )

MA = Reação de Microaglutinação; Soros testados nas diluições 1/5 até 1/32 


\section{Discussão}

Os camundongos constituem cerca de $90 \%$ dos animais de laboratório utilizados em pesquisa e ensino. A presença de microrganismos patogênicos, mesmo que em infecções subclínicas, é um fator importante pela possibilidade de ocorrerem infecções oportunistas que podem colocar em risco a saúde dos animais, e em casos de zoonoses, a saúde humana.

Os parâmetros biológicos alterados podem se refletir em mudanças de comportamento, taxa de crescimento, níveis enzimáticos, resposta imune e índices de produtividade. O monitoramento sanitário a periódico é importante para assegurar o status microbiológico e a qualidade do animal, além de servir de base para orientar tomadas de decisões, na tentativa de correção de erros de manejo na produção dos animais e durante a análise de dados de pesquisa.

Em colônias convencionais de animais de laboratório são comuns as infecções parasitárias por oxiurídeos, mesmo na presença de barreiras sanitárias. A infestação de animais pode ocorrer por ingestão de ovos embrionados através de aerossóis enquanto os animais se limpam durante trocas de caixas. Apesar das lesões causadas por oxiurídeos serem raras, infestações severas podem causar irritabilidade e desconforto nos animais, levando a alteração de parâmetros fisiológicos e debilidade. Um estudo mostrou a porcentagem de infecção por ecto e endoparasitas em camundongos e ratos de cinco biotérios do estado de São Paulo, sendo em média 57\% para Syphacia spp. e 50\% para Aspiculuris tetraptera (Bressan et al., 1997). Outro estudo realizado em dezoito biotérios brasileiros com diferentes padrões sanitários demonstrou prevalência de infecção de $86.6 \%$ pela Syphacia obvelata e $60.0 \%$ pelo Aspiculuris tetraptera, entre outros parasitas (Gilioli et al., 2000). O presente trabalho mostrou 30\% de animais infectados por oxiurídeos. Apesar da taxa de infecção ser mais baixa do que as relatadas na literatura podemos considerar que toda colônia está infectada.

A presença de Staphylococcus aureus em 30\% das amostras de traqueia pode ser devida à contaminação da pele, durante o procedimento de coleta. Também merece atenção a presença de Trichophyton mentagrophytes na 
grade dos animais, que representa uma potencial fonte de infecção para os animais e o homem. O restante dos organismos identificados são bactérias encontradas na microbiota normal de animais convencionais.

O fato de o presente estudo estar avaliando animais em condições sanitárias convencionais, em um biotério com apenas algumas barreiras sanitárias estabelecidas, merece ser discutido. As barreiras utilizadas são portas fechadas, impedindo a entrada de outros vertebrados na área de manutenção dos animais, controle de entrada de animais provenientes de outros biotérios, fluxo unidirecional dos materiais utilizados de área limpa para suja e autoclavagem da maravalha. Não existe controle de eficiência das barreiras, nem controle e validação dos processos de limpeza e de esterilização. Mesmo nas condições descritas, os organismos encontrados colonizando os camundongos avaliados são considerados não patogênicos.

O sucesso tanto da produção de animais, como da utilização destes em procedimentos experimentais, depende principalmente da conscientização dos técnicos e pesquisadores, em conjunto com a implantação de transformações que visem reestruturação física e refinamento de procedimentos operacionais (Oliveira, 2003). É necessário trabalhar com pessoal técnico treinado e capacitado para manipulação dos animais; possuir protocolos de avaliação das condições sanitárias dos animais e do ambiente no qual estes se encontram; e respeitar as exigências éticas e legislativas sobre o uso de animais na pesquisa. Isto só pode ser obtido através de um esforço conjunto entre profissionais que trabalham diretamente na manutenção dos animais, pesquisadores e a administração da instituição.

\section{Conclusões}

Algumas conclusões importantes podem ser tiradas com base nos resultados encontrados nesse trabalho:

- Apesar do biotério do ILSL ser instalado em condições convencionais sem controle de barreiras sanitárias, não há indicação da existência de 
importantes patógenos para os animais, nem para os técnicos que manipulam os animais, o que indica que as barreiras estabelecidas (controle de entrada de animais externos e pessoas, esterilização de cama) têm sido efetivas no controle de contaminação do meio externo para o interno.

- A presença de helmintos na colônia indica que o manejo dos animais em seu micro-ambiente, a higiene pessoal e ambiental devem ser melhorados de forma a evitar re-infecção dos animais.

- A caracterização da microbiota torna mais fácil a identificação de microrganismos para diagnóstico e controle de enfermidades.

- O monitoramento sanitário é um procedimento importante para auxiliar na validação de métodos operacionais que visem a obtenção de animais de qualidade para uso na pesquisa científica.

- Considerando a importância do monitoramento realizado, a metodologia aplicada revela grande valor prático, devendo ser implantada como rotina neste biotério.

\section{Referências Bibliográficas}

BRESSAN, M.C.R.V., CALGARO, G.A., ALEXANDRE, S.R., MARQUES T. Prevalence of ecto and endoparasites in mice and rats reared in animal houses. Bras J Vet Res Anim Sci, v.34, p.14246, 1997.

CARDOSO, T.A.O. Considerações sobre a biossegurança em arquitetura de biotérios. Bol Centr Panam Fiebre Aftosa; v.64-67, p.3-17, 1998-2001.

GILIOLI, R., ANDRADE, L.A.G., PASSOS, L.A.C., SILVA, F.A., RODRIGUES D.M., GUARALDO, A.M.A. Parasite survey in mouse and rat colonies of Brazilian laboratory animal houses kept under different sanitary barrier conditions. Arq Bras Med Vet Zootec, v.52, 2000.

LUCA, R.R., ALEXANDRE, S.R., MARQUES, T., SOUZA, N.L., MERUSSE, J.L.B. Manual para Técnicos em Bioterismo. 2 ed. São Paulo: Winner Graph, 1996.

MOLINARO, E. M.; MAJEROWICZ, J.; COUTO, S. E.R.; BORGES, C.C. A.; MOREIRA,W.C.; RAMOS, S. Animais de laboratório. In:Conceitos e métodos para a formação de profissionais em laboratórios de saúde. Janeiro: EPSJV; IOC; v.1, cap.4, p.155-222, 2009.

OLIVEIRA, G.M. Conscientização e Implantação de Transformações Institucionais. Parte I de III. Controle de Contaminação, v.55, p.20-26, 2003. 
RAYMUNDO, M.M., GOLDIM, J.R. Ética da pesquisa em modelos animais. Bioética, v.10, p.3144, 2002. 